\title{
Lung ultrasound-guided surfactant administration: time for a personalized, physiology-driven therapy
}

\author{
Francesco Raimondi ${ }^{1}$ J. Peter de Winter ${ }^{2,3}$ - Daniele De Luca ${ }^{4,5}$ \\ Published online: 24 July 2020 \\ (C) Springer-Verlag GmbH Germany, part of Springer Nature 2020
}

Neonatal lung ultrasound is a novel imaging technique that is gathering growing interest in neonatal intensive care units (NICU). Functional lung ultrasound is able to document the failure of non-invasive respiratory support that often preludes to exogenous surfactant administration for respiratory distress syndrome (RDS) [1].

The current European guidelines for the administration of surfactant only rely on the need for a certain inspiratory oxygen fraction threshold [2]. This, however, has a weak evidence background mainly coming from a single, small-sized, singlecenter, retrospective study [3]. Moreover, inspired oxygen fraction $\left(\mathrm{FiO}_{2}\right)$ cannot give any accurate description of the oxygenation status, as it does not take into consideration many important variables that significantly influence oxygenation, such as the constant distending pressure provided to the patient, arterial oxygen pressure, temperature, peripheral perfusion, hemoglobin concentration, and the extremely variable level of fetal hemoglobin, just to name a few.

Unsurprisingly, the American Academy of Pediatrics guidelines on surfactant replacement do not recommend any $\mathrm{FiO}_{2}$ thresholds to give surfactant and only highlight that surfactant should be given as early as possible in the process of RDS [4]. On the same line, it is not surprising that severe

Daniele De Luca

dm.deluca@icloud.com

1 Department of Translational Medical Sciences, Division of Neonatology, Federico II University, Naples, Italy

2 Department of Pediatrics, Spaarne Gasthuis, Hoofddorp Haarlem, The Netherlands

3 Department of Development and Regeneration, KU Leuven, Leuven, Belgium

4 Division of Pediatrics and Neonatal Critical Care, "A. Beclere" Medical Center, Paris Saclay University Hospitals APHP, Paris, France

5 Physiopathology and Therapeutic Innovation Unit, INSERM U999 Paris Saclay University, Paris, France respiratory failure in adults and children $[5,6]$ is not evaluated by using only $\mathrm{FiO}_{2}$, which is not a criterion for the definition of neonatal, pediatric, or adult ARDS neither $[5,7,8]$.

However, there are enough evidence-based data to give surfactant as early as possible (that is, within the first 3 hours of life) [9] in preterm neonates affected by RDS treated with continuous positive airway pressure (CPAP) and all guidelines recognize this $[2,4]$.

Thus, here we have a substantial problem. We should make a diagnosis of RDS in CPAP-treated preterm neonates and identify those patients who will fail CPAP and need surfactant replacement and those who will not fail CPAP and may spare the treatment. More and above this, we need to do this investigation is a short period ( 3 hours), which is shorter than it may seem when one is diving into routine neonatal critical care in a very busy NICU.

Complex and important problems in clinical medicine are not likely to have an easy solution. In fact, $\mathrm{FiO}_{2}$ alone misses several oxygenation variables and, because of its inaccuracy, may lead to unnecessary surfactant administration with unwanted consequences (need for sedation, desaturation, etc.) or to delayed surfactant administration and reduced therapeutic efficacy when the need for oxygen rises only late. These are everyday experiences for NICU practitioners.

An utterly innovative strategy is represented by the use of semi-quantitative lung ultrasound which is not evaluating the oxygenation, but it is instead "visualizing" lung disease. In fact, lung ultrasound scores accurately estimate lung aeration, which is the amount of lung volume available for gas exchange, as this has been demonstrated in a plethora of animal and human studies [10]. For a uniform, homogeneous, and restrictive lung disease due to primary surfactant deficiency, the estimation of lung aeration is equivalent to an accurate description of oxygenation. In fact, lung ultrasound score accurately correlates, not with $\mathrm{FiO}_{2}$, but with all more sophisticated oxygenation metrics [11-13] that take into account at least some of the factors mentioned above that influence oxygenation status. Thus, lung ultrasound represents a mindset 
change and also a more pathophysiological approach to a complex problem that cannot be simplified.

A recent quality improvement project showed that when surfactant is given based on lung ultrasound score (versus the oxygen requirement), more babies received surfactant within 3 hours of life with less oxygen exposure; this has been called ESTHER (Echography-guided Surfactant THERapy) [14]. Rodriguez Fanjul and coworkers should be commended for being the first colleagues to confirm these results in a randomized controlled trial where lung ultrasound score and $\mathrm{FiO}_{2}$ thresholds are compared [15]. They applied the ESTHER policy and, notably, all infants in the first group reached the lung ultrasound score threshold before the momentous brink of $0.3 \mathrm{FiO}_{2}$ demand and received surfactant within the first hour of life (versus 6 hours in the control group). Together, these two papers provide good evidence for a timelier and more physiology-based surfactant administration in preterm babies with RDS [14, 15]. Interestingly, the lung ultrasound-guided surfactant replacement reduced oxygen exposure but did not change the overall surfactant use. This is also important and consistent with data shown even in larger populations [16].

The study has its limitations as any other. For instance, the small sample size, the lack of blindness, and the enrolment of preterm neonates less than 32 weeks' gestation rather than a population of extremely preterm infants [15]. However, the authors recognize these limitations, and their results are based on a solid pathophysiological background described above and supported by a large consisting adult critical care literature [10].

Surfactant has been given as almost universal prophylaxis at birth for years, then the need for an early rescue therapy has been finally recognized. Now, the time has come for an even more personalized, timely, physiology-driven treatment. This can only improve the general quality of neonatal care as lung ultrasound is non-invasive and requires minimal training and tools that are available also in low-income countries $[17,18]$. More and above this, the ultrasound-guided surfactant administration can eventually improve important clinical outcomes, through the reduction of oxygen exposure and ventilatory need [9], provided by an earlier and more effective surfactant replacement in patients who really need it.

Author Contribution Francesco Raimondi reviewed the ULTRASURF trial and commented it, writing this editorial draft.

Peter de Winter and Daniele De Luca evaluated the review, did the literature search, suggested important changes to the ULTRASURF trial and provided critical intellectual comments to this editorial.

Daniele De Luca, conceived this editorial and supervised its preparation.

All authors approved the final version of this editorial.

\section{References}

1. Raimondi F, Yousef N, Migliaro F, Capasso L, de Luca D (2018) Point-of-care lung ultrasound in neonatology: classification into descriptive and functional applications. Pediatr Res. https://doi. org/10.1038/s41390-018-0114-9

2. Sweet DG, Carnielli V, Greisen G, Hallman M, Ozek E, te Pas A, Plavka R, Roehr CC, Saugstad OD, Simeoni U, Speer CP, Vento M, Visser GHA, Halliday HL (2019) European Consensus guidelines on the management of respiratory distress syndrome -2019 Update. Neonatology 115:432-450. https://doi.org/10.1159/ 000499361

3. Dargaville PA, Aiyappan A, De Paoli AG et al (2013) Continuous positive airway pressure failure in preterm infants: incidence, predictors and consequences. Neonatology 104:8-14. https://doi.org/ $10.1159 / 000346460$

4. Polin RA, Carlo WA, Committee on Fetus and Newborn (2014) Surfactant replacement therapy for preterm and term neonates with respiratory distress. Pediatrics 133:156-163. https://doi.org/10. 1542/peds.2013-3443

5. (2012) Acute respiratory distress syndrome: the Berlin definition. JAMA 307. https://doi.org/10.1001/jama.2012.5669

6. On behalf of Respiratory Section of the European Society for Pediatric Neonatal Intensive Care (ESPNIC), De Luca D, Piastra $\mathrm{M}$ et al (2013) The use of the Berlin definition for acute respiratory distress syndrome during infancy and early childhood: multicenter evaluation and expert consensus. Intensive Care Med 39:20832091. https://doi.org/10.1007/s00134-013-3110-x

7. Khemani RG, Smith LS, Zimmerman JJ, Erickson S (2015) Pediatric acute respiratory distress syndrome: definition, incidence, and epidemiology. Pediatr Crit Care Med 16:S23-S40. https://doi. org/10.1097/PCC.0000000000000432

8. De Luca D, van Kaam AH, Tingay DG et al (2017) The Montreux definition of neonatal ARDS: biological and clinical background behind the description of a new entity. Lancet Respir Med 5:657666. https://doi.org/10.1016/S2213-2600(17)30214-X

9. Bahadue FL, Soll R (2012) Early versus delayed selective surfactant treatment for neonatal respiratory distress syndrome. Cochrane Database Syst Rev. https://doi.org/10.1002/14651858.CD001456. pub2

10. De Luca D (2019) Semiquantititative lung ultrasound scores are accurate and useful in critical care, irrespective of patients' ages: the power of data over opinions. J Ultrasound Med 39:1235-1239. https://doi.org/10.1002/jum.15195

11. Brat R, Yousef N, Klifa R et al (2015) Lung ultrasonography score to evaluate oxygenation and surfactant need in neonates treated with continuous positive airway pressure. JAMA Pediatr 169: e151797. https://doi.org/10.1001/jamapediatrics.2015.1797

12. De Martino L, Yousef N, Ben-Ammar R et al (2018) Lung ultrasound score predicts surfactant need in extremely preterm neonates. Pediatrics 142(3):e20180463. https://doi.org/10.1542/peds.20180463

13. Raimondi F, Migliaro F, Verdoliva L, Gragnaniello D, Poggi G, Kosova R, Sansone C, Vallone G, Capasso L (2018) Visual assessment versus computer-assisted gray scale analysis in the ultrasound evaluation of neonatal respiratory status. PLoS One 13:e0202397. https://doi.org/10.1371/journal.pone.0202397

14. Raschetti R, Yousef N, Vigo G, Marseglia G, Centorrino R, BenAmmar R, Shankar-Aguilera S, de Luca D (2019) Echographyguided surfactant therapy to improve timeliness of surfactant replacement: a quality improvement project. J Pediatr 212:137143.e1. https://doi.org/10.1016/j.jpeds.2019.04.020 
15. Fanjul R (2020) Early surfactant replacement guided by lung ultrasound in preterm newborns with RDS: the ULTRASURF randomised controlled trial. Eur J Pediatr. https://doi.org/10.1007/ s00431-020-03744-y

16. De Luca D, Yousef N (2020) Pharmaceutical expenditure is unchanged with ultrasound-guided surfactant administration. Am J Perinatol (in press 2020)

17. Mazmanyan P, Kerobyan V, Shankar-Aguilera S, Yousef N, de Luca D (2020) Introduction of point-of-care neonatal lung ultrasound in a developing country. Eur J Pediatr 179:1131-1137. https://doi.org/10.1007/s00431-020-03603-w

18. for the Lung Ultrasound Consortium, Vercesi V, Pisani L, et al (2018) External confirmation and exploration of the Kigali modification for diagnosing moderate or severe ARDS. Intensive Care Med 44:523-524. https://doi.org/10.1007/s00134-018-5048-5

Publisher's note Springer Nature remains neutral with regard to jurisdictional claims in published maps and institutional affiliations. 